Trst

\title{
LA i PARASSITA NELLO SLOVENO TRIESTINO
}

Lo spoglio di due dei tre maggiori archivi medioevali triestini' ha già consentito di proporre datazioni di fenomeni dialettali sloveni difformi da quelle proposte dal Ramovš̌ ; si è potuto così appurare che la moderna riduzione vocalica ("moderna vokalna redukcija") e il passaggio della $t$ anteconsonantica e finale a $u$ avvengono a Trieste almeno un secolo prima, forse anche un secolo e mezzo, che non nella Slovenia centrale. Per quanto concerne il passaggio $t>u$ si pone pure il quesito di un parallelismo - o addirittura di una priorità - tra il tergestino e lo sloveno locale.

Qui si desidera prospettare il caso di un fenomeno dialettale sorto nello sloveno triestino sincronicamente ai dialetti della Slovenia centrale: le constatazioni del Ramovš concordano infatti appieno con le testimonianze offerte dagli archivi tardomedioevali triestini. Ci riferiamo alla $i$ parassita, che il Ramovš denomina "prehodni $i^{\prime}$. Si veda in proposito la ricchissima casistica addotta dal Ramovš ${ }^{3}$ che testimonia la presenza della $i$ parassita a partire dai protestanti sloveni della metà del XVI secolo fino ai dialetti attuali. Già all'inizio della trattazione il Ramovšs sottolinea il carattere irregolare del fenomeno.

Le testimonianze degli archivi triestini del tardo medioevo consentono di affermare che il fenomeno non si è verificato a Trieste prima che nella Slovenia centrale, infatti non se ne incontra nemmeno un caso nell'onomastica personale e locale negli ultimi secoli del medioevo. La testimonianza più antica riguarda il nome personale Moça: R 1308-1310 a Moça uxore Volcine Sbriga oleo (carte 11 recto e 56 recto) ${ }^{4}$; lo stesso nome personale femminile compare per un altro soggetto in P $1312 \mathrm{Moça}$, moglie di Pietro becaro; e per un terzo soggetto in P 1315 donna Moça, vedova di Jure Masche, (dal regesto italiano risulta evidente un genitivo latino del soprannome o cognome Mačka) ha una vigna in contrada Ligoxel, Q 1316 a Moça de Iuri Maçcha (carte 9 recto e 13 recto). Sei reperti per tre soggetti riportano la stessa forma nominale nella stessa grafia e ne evinciamo il nome personale femminile $M o ́ c a$ rapportabile al moderno $M o ́ j c a$, ipocoristico di Marija, con la $i$ parassita, e al nome

1 Per la descrizioni degli archivi e le abbreviazioni si rimanda a "Patronimici in -ič a Trieste nel basso medioevo" dello stesso autore in Linguistica XXIV, Ljubljana 1984, pag. 275 sgg.

2 "Prehod $l \vee u v$ tržaški slovenščini" dello stesso autore in Slavistična revija, Ljubljana 1983/3, pagg. $260-262$.

3 F. Ramovš, Historična gramatika slovenskega jezika II, Konzonantizem, Ljubljana 1924, pagg. 170-176. Secondo il Ramovš la $i$ parassita ("prehodni $i^{\text {") }}$ ) si sviluppa tra una vocale tonica, esclusa la $i$, e una consonante dentale, soprattutto una spirante o affricata, più raramente una occlusiva, con caratteristiche personali e locali aleatorie.

4 Con l'abbreviazione $\mathbf{R}$ si designa il codice Redditus et proventus beneficiorum Canonicalium Ven. Capituli Tergestini de Anno 1310, Archivio capitolare di S. Giusto, Trieste. 
personale croato $M a ́ c a$, ipocoristico di Marija, ovviamente sprovvisto della $\underset{i}{i}$ parassita.

La casistica triestina continua, per il XIV secolo, con il toponimo BM $1354 A n$ dreas de Voscischa ${ }^{5}$, RP 1377? (comunque sicuramente entro il XIV secolo) a Mat-

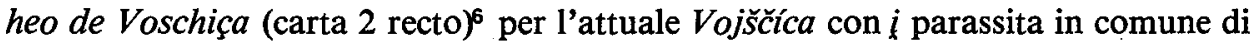
Nova Gorica ${ }^{7}$ e 14.. Giorgio de Ostreviça basiach ladro ${ }^{8}$, ove il toponimo non è riferibile con certezza ad alcuna località nota, mentre è di pubblico dominio l'attuale pronuncia della base aggettivale ójster, che compare nel toponimo, con $i$ parassita, $\mathrm{e}$ in tutti i derivati in tutte le forme dialettali parlate nelle province di Trieste e Gorizia e nei comuni della Repubblica socialista di Slovenia a ridosso dell'attuale confine di Stato.

L'assenza di ogni traccia di $i$ parassita negli archivi del tardo medioevo triestino e la sua apparizione negli scritti di Sebastijan Krelj, il primo scrittore protestante proveniente dall'Occidente sloveno, consente di datare il fenomeno nei dialetti occidentali entro la prima metà del ' 500 in sincronia con quanto il Ramovš rileva per la Slovenia centrale.

\section{Povzetek \\ PREHODNI $i$ V TRŽAŠKI SLOVENŠČINI}

Pregled imenskih oblik v dveh od treh pomembnih tržaških srednjeveških arhivov je že omogočil za tržaško slovenščno drugačno datacijo nekaterih jezikovnih pojavov od onih, ki jih je ugotovil Ramovš za osrednja narečja. V primeru prehodnega $i$ pa se tržaška slovenščina ujema $z$ Ramovševimi časovnimi ugotovitvami, ki veljajo za osrednja narečja: v poznem srednje veku in sicer v 14. in 15. stoletju izpričujejo namreč tržaški viri izključno imenske oblike brez parazitskega glasu (Moça: Mojca, Voschiça: Voǰč̌ica, Ostreviça: ojster). Očitno je pojav datirati tudi v Trstu v prvi polovici 16. stol., tako kakor je Ramov̌̌ ugotovil za Sebastijana Krelja in sicer ̌̌ za ves slovenski prostor.

Con l'abbreviazione BM si designa Bancus maleficiorum, Archivio diplomatico, Trieste.

Con l'abbreviazione RP si designa il codice Redditus et proventus Canonicorum et Capituli Ecclesiae Tergestinae de 1377 et sparsim de pluribus annis sub eodem milessimo, Archivio capitolare di S. Giusto, Trieste.

7 Per l'etimologia da $(v) g z \zeta k z$ cfr. F. Bezlaj, Slovenska vodna imena II, Ljubljana 1961, pag. 309.

8 J. Cavalli, Comercio e vita privata a Trieste nel 1400, Trieste 1900, pag. 124. 